\title{
¿Adobes, terrones o bolas de barro amasado? Aportaciones para el reconocimiento arqueológico de las distintas técnicas constructivas que emplean módulos de tierra
}

\section{María Pastor Quiles", Franziska Knoll ${ }^{* * *}$ y Francisco J. Jover Maestre ${ }^{* * *}$}

Recibido: 27 de febrero de 2018

Aceptado:

21 de diciembre de 2018

\section{Resumen}

En contextos arqueológicos es habitual la documentación de estructuras inmuebles en las que se emplea la tierra como material constructivo. Entre las técnicas constructivas con tierra que emplean elementos modulares se encuentran el adobe, el amasado de barro y el terrón. No obstante, a pesar de ser técnicas reconocidas y haber sido empleadas hasta la actualidad, en los estudios arqueológicos se encuentran importantes dificultades para su reconocimiento. La importancia de su correcta identificación reside, sobre todo, en las implicaciones económicas y sociales que se derivan de su aplicación y desarrollo. Con este trabajo abordamos la caracterización de las distintas técnicas señaladas, con el objetivo de contribuir a una mejor diferenciación entre ellas. A través de su descripción y análisis, atendiendo principalmente a sus características macroscópicas, y de la presentación de un caso de estudio específico de la Edad del Bronce de la península ibérica, se aporta una serie de consideraciones orientadas a concretar qué criterios pueden permitir un mejor reconocimiento de estas técnicas, atendiendo especialmente a su estudio como unidades individualizadas.

Adobe, sod blocks or cob balls? Contributions to the archaeological identification of the different building techniques that use earthen units

\footnotetext{
Abstract

The documentation of structures built with earth in the archaeological record is common. Among the earth construction techniques that use modular units, we find adobe (mud bricks), cob and sod. Despite being recognized techniques that are still

* Departamento de Prehistoria, Arqueología, Historia Antigua, Filología Griega y Filología Latina. Universidad de Alicante. Carretera de San Vicente del Raspeig s/n (CP 0369o), San Vicente del Raspeig, Alicante, España. E-mail: m.pastor@ua.es

** Institut für Kunstgeschichte und Archäologien Europas, Prähistorische Archäologie und Archäologie des Mittelalters und der Neuzeit. Martin-Luther-Universität Halle-Wittenberg. Emil-Abderhalden-Strasse 26-27 (CPo6108) Halle (Saale), Alemania. E-mail: franziska.knoll1@gmx.de

*** Instituto Universitario de Investigación en Arqueología y Patrimonio Histórico (INAPH). Universidad de Alicante. Carretera de San Vicente del Raspeig s/n (CP 0369o) San Vicente del Raspeig, Alicante, España. E-mail: javier.jover@ua.es
}

\section{Palabras clave}

Construcción con tierra Arqueología

Técnicas de construcción Adobe

Terrón

Amasado en forma de bolas 
Keywords

Earth construction Archaeology Construction techniques Adobe in use nowadays, it is difficult to differentiate them in archaeological reports. Their correct identification is important because of the economic and social implications of their application and development. This paper addresses the characterization of these techniques in order to contribute to their better identification. Through their description and analysis, and the presentation of a specific case study from the Bronze Age in the Iberian Peninsula, we propose different criteria to recognize the different modular earth building techniques, especially based on the study of the individualized units.

\section{Introducción}

La tierra y los elementos vegetales han sido las materias primas más utilizadas como materiales constructivos a lo largo de la Historia de la Humanidad. La experiencia y el conocimiento acumulado sobre las propiedades de la tierra posibilitaron el desarrollo de distintas técnicas (Doat, Hays, Houben, Matuk y Vitoux, 1979; Houben y Guillaud, 1993; Minke, 2001; Knoll, Pastor Quiles, De Chazelles y Cooke, en prensa, entre otros), ya ampliamente utilizadas por diferentes sociedades prehistóricas. El desarrollo de las prácticas de edificación supuso, en muchos casos, la progresiva introducción de mejoras en la durabilidad de los espacios construidos (Guerrero Baca, Soria y García, 2010; Jover Maestre, Pastor Quiles, Martínez Mira y Vilaplana Ortego, 2016), ampliando las posibilidades en cuanto a la elección y puesta en obra de los distintos materiales y produciéndose un empleo predominante de la tierra sobre otros elementos como la piedra, sobre todo en territorios donde ésta última era de difícil obtención.

A pesar de que el uso del barro en las labores constructivas en cierto modo ya estaría presente en el seno de grupos cazadores-recolectores, junto con la madera y los elementos vegetales, las investigaciones desarrolladas hasta la fecha vienen apuntando que el desarrollo de la edificación con tierra se asocia, en primera instancia, con la sedentarización y con grupos de base agropecuaria, una vez consolidados territorial y socialmente. El hecho de que en diferentes partes del planeta se comenzara a emplear también la piedra como material constructivo no supuso un menor uso del barro y la materia vegetal, sino, más bien, la combinación de las distintas materias primas, según las condiciones materiales existentes y las distintas tradiciones, ampliándose los conocimientos y las opciones técnicas de su puesta en obra.

El desarrollo técnico gestado en el proceso histórico es el que ha posibilitado distintas formas en el empleo de la tierra como material de construcción. De ese modo, en la investigación desarrollada en arquitectura y arqueología se diferencian, por un lado, las técnicas constructivas "mixtas" (Doat et al., 1979: 220; Viñuales, Martins Neves, Flores y Silvio Ríos, 2003, p. 37, entre otros), en las que este material no realiza la función portante y, por otro, las técnicas de "tierra masiva" (Avrami, Guillaud y Hardy, 2008; De Chazelles, 1999; Guillaud, De Chazelles y Klein, 2007, entre otros), en las que las partes de la edificación construidas con tierra soportan las cargas de la estructura.

Es en esta última agrupación donde se incluyen las diferentes formas de construir que emplean unidades individualizadas o módulos de tierra como material constructivo, apilados o unidos entre sí. En este conjunto, se diferencian tres técnicas constructivas principales: 1) el amasado de barro dispuesto en forma de bolas o bloques, formados en estado húmedo, 2) el adobe, fabricado a mano o con molde, aplicado una vez que los bloques están secos y 3 ) el empleo de bloques de tierra natural, cortados y extraídos directamente del suelo, que denominamos terrones. 
Aunque el uso de cada una de estas formas de construir es diferente, requiriendo una serie de condiciones materiales, técnicas y organizativas diferenciadas en la esfera de lo social, no siempre es una tarea sencilla distinguirlas entre sí a partir de las evidencias conservadas en el registro arqueológico. Por esta razón, con este texto queremos contribuir a su mejor reconocimiento arqueológico a partir de la definición de sus características, así como su comparación, proponiendo algunos criterios que pueden ayudar en su diferenciación. Este trabajo se acompaña además de la presentación de un caso de estudio relevante para el problema planteado.

\section{Bolas de barro, adobes y terrones: elementos modulares obtenidos mediante distintas técnicas}

Bolas de barro, adobes y terrones son elementos modulares producidos en el marco del empleo de distintas técnicas constructivas. Si queremos avanzar hacia una mejor diferenciación entre ellas, en especial desde una perspectiva arqueológica, debemos partir de su definición y caracterización teórica.

\section{Bolas o bloques de barro amasado}

En lo referente al empleo de unidades individualizadas elaboradas con barro en el marco de la técnica constructiva del amasado, el material se dispone directamente desde el proceso de elaboración de la mezcla y en estado húmedo (Bardou y Arzoumanian, 1986; Doat et al., 1979, entre otros), modelándose, apilándose o lanzándose con las manos o mediante el empleo de un instrumento. El lanzado o aplastado del barro se relaciona con la obtención de una mayor compactación y resistencia del mortero, ya que la unión del material se realiza mediante estos procesos mecánicos (Gauzin-Müller, 2017; Minke, 2001). En este sentido, el barro también puede disponerse en forma de unidades individualizadas, sean bolas, bloques o "panes" (Aurenche, Klein, De Chazelles y Guillaud, 2011, p. 20; Guerrero Baca, 2018; Houben y Guillaud, 1993; Minke, 2001, entre otros), según su diferente morfología (Figura 1A). Estas piezas amasadas de barro se disponen directamente unas sobre otras con anterioridad a su secado completo, conservando su forma inicial (Figura 1B), aunque los contornos de la estructura puedan ser modelados, otorgándole una apariencia uniforme.

El barro puede modelarse en forma de bolas o de bloques por diversas razones, aunque principalmente atendiendo a criterios de eficacia laboral y comodidad a la hora de transportar el material, desde el espacio donde se ha realizado la mezcla hasta la construcción en curso. De hecho, a nivel general, en los procesos de amasado del barro la ejecución de formas esféricas o semiesféricas es común, algo que puede verse en el amasado de arcilla para hacer cerámica, pero también en la actividad productiva de rellenar manualmente moldes para realizar adobes. Así, el barro que se toma con las manos para su puesta en obra mediante la técnica del amasado constituiría inicialmente unidades individualizadas, con independencia de su morfología y dimensiones. No obstante, a continuación, esta frecuentemente se regulariza, disimulándose su forma inicial, en ocasiones mediante golpes con una tabla de madera, como en el caso del cob inglés. Las unidades individualizadas de amasado de barro también se pueden utilizar para reparar determinadas partes de los muros o para aplicar revestimientos de tierra, colocando las bolas unas junto a otras en las superficies verticales de los alzados (Dethier, 1982). Además, con esta técnica pueden construirse también estructuras de actividad y almacenaje, como hornos o silos edificados (Guidoni, 1977).

Son pocos los ejemplos arqueológicos conocidos de la aplicación de la técnica del amasado de barro en forma de bolas. Ha sido identificada en asentamientos tan antiguos como Klimonas (Ayios Tychonas, Chipre; Mylona, Wattez, Franel y Vigne, 2017), datado en el Neolítico Precerámico, hacia el IX milenio BC, o en asentamientos 

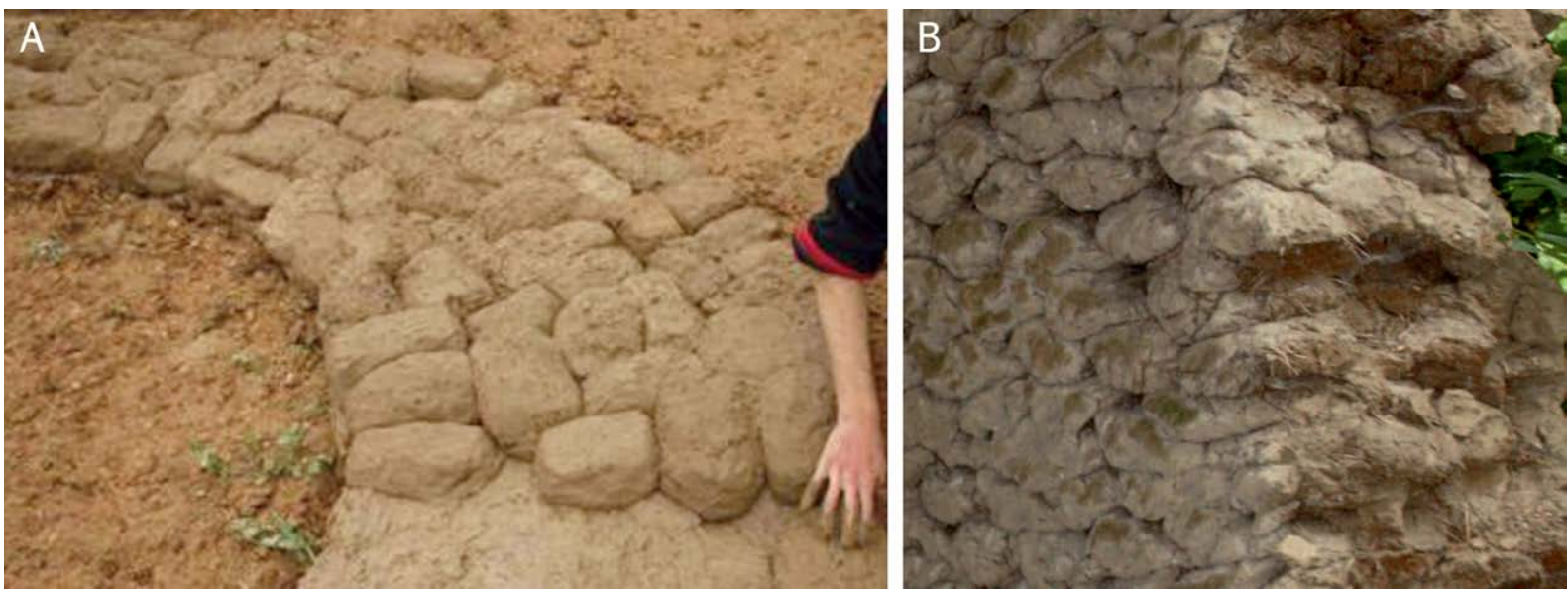

Figura 1. A) Construcción experimental mediante bloques amasados de barro (Jallot y Wattez, 2015: 11); B) alzado de módulos de barro amasado. Slup, República Checa (Schäfer, 2014, p. 2).

más recientes de mediados del III milenio BC, como La Capoulière (Gutherz et al., 2011; Mauguio, Francia; Wattez, 2003). En cambio, a nivel etnográfico, esta técnica se documenta en diferentes lugares de África (Agorsah, 1985; Baloi, 2011; Guidoni, 1977) y Asia, por ejemplo, en Yemen, donde recibe el nombre de zabur (Wright, 2009: 569). Recientemente ha sido publicado su empleo por parte de poblaciones nativas de Norteamérica en Albuquerque, Nuevo México (Mileto y Vegas López-Manzanares, 2018). También se conoce su uso en Europa occidental durante la Edad media, moderna y contemporánea, en países como Bélgica (Bavay, 2006), Francia (Bardel y Rioult, 2006; Klein, 2003), Alemania (Güntzel, 1986; Volkskundliche Kommission für Thüringen e.V, 2009) y la República Checa (Syrova y Syrovy, 2006).

\section{Adobes}

La segunda técnica constructiva a considerar que utiliza el empleo de módulos de tierra es el adobe. En esta forma de construir, la más conocida y abordada de las que aquí tratamos, se emplean unidades elaboradas con barro, prefabricadas en serie, puestas en obra ya secas y generalmente unidas con mortero. Los adobes son elementos modulares de tierra que adquieren su endurecimiento secándose al aire - las piezas de barro cocidas reciben el nombre de ladrillos (sobre las diferencias entre ambos módulos, cocidos y no cocidos, ver por ejemplo Ontiveros Ortega, 2008) - . Los adobes pueden fabricarse a mano (Figura 2) o mediante un molde, generalmente hecho de madera (Figura 3). El desarrollo de la técnica del adobe hecho a mano se considera previo a la del adobe fabricado con molde. En algunos casos, el molde puede haber sido realizado con materia vegetal dura, como es el caso de las cañas, quedando las improntas de estas en los laterales del adobe (Chirinos Cuadros y Zárate Aguinaga, 2011; Guillaud, 2011).

Por otro lado, los adobes fabricados a mano suelen presentar marcas en la superficie de una de sus caras, generalmente hechas con los dedos que, entre otras funciones posibles, facilitan la adhesión del mortero que los une (Asensio Esteban, 1995; Aurenche, 1981, entre otros). La presencia de este tipo de marcas no es exclusiva de la producción de adobes a mano, dándose también en los producidos con molde (Fatás Fernández y Catalán Garzarán, 2005; Nodarou, Frederick y Hein, 2008, Figura 3B). Con adobe pueden construirse alzados, tabiques internos y plementos, arcos, bóvedas, cúpulas y cubiertas planas (Stevanović, 2013).

Los adobes fabricados a mano se documentan en distintas regiones del mundo, como en el Próximo Oriente asiático, ya en asentamientos neolíticos precerámicos 

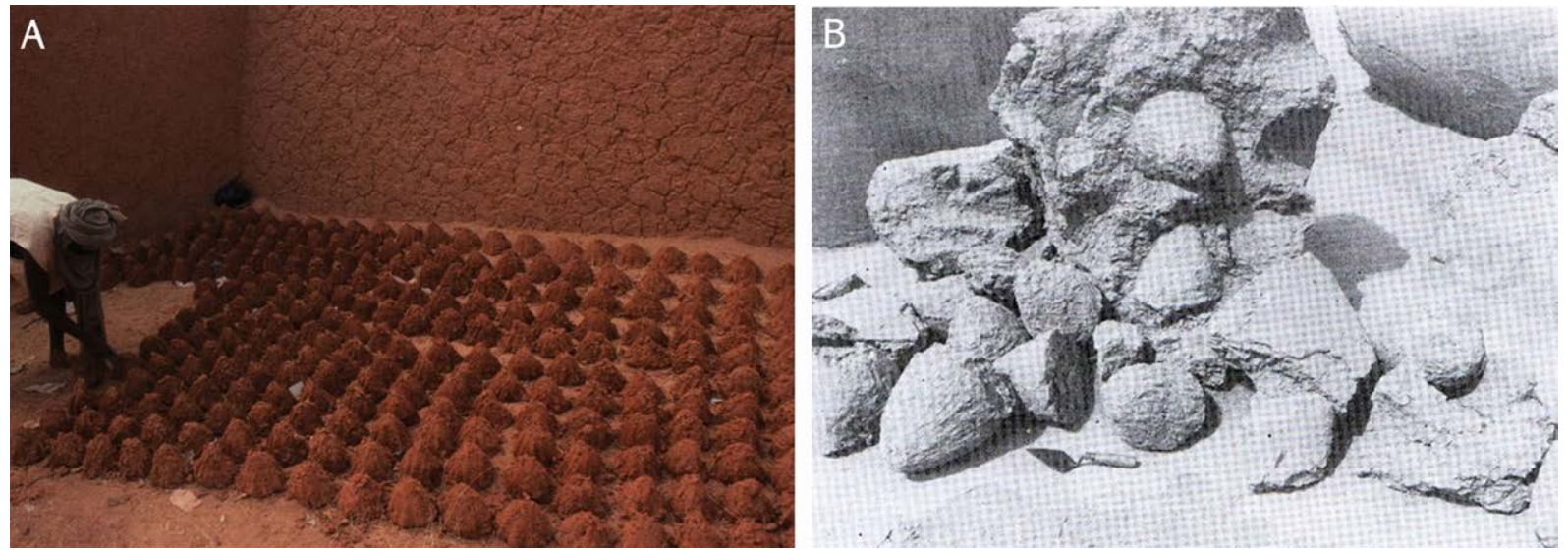

Figura 2. A) Producción de adobes hechos a mano -tubali- en Nigeria (Guillaud, 2011, figura 7); B) derrumbe de adobes hechos a mano, de forma cónica, en Huaca Lucía (Lambayeque, Perú), III milenio cal BC (Chirinos y Zárate, 2011, p. 65).
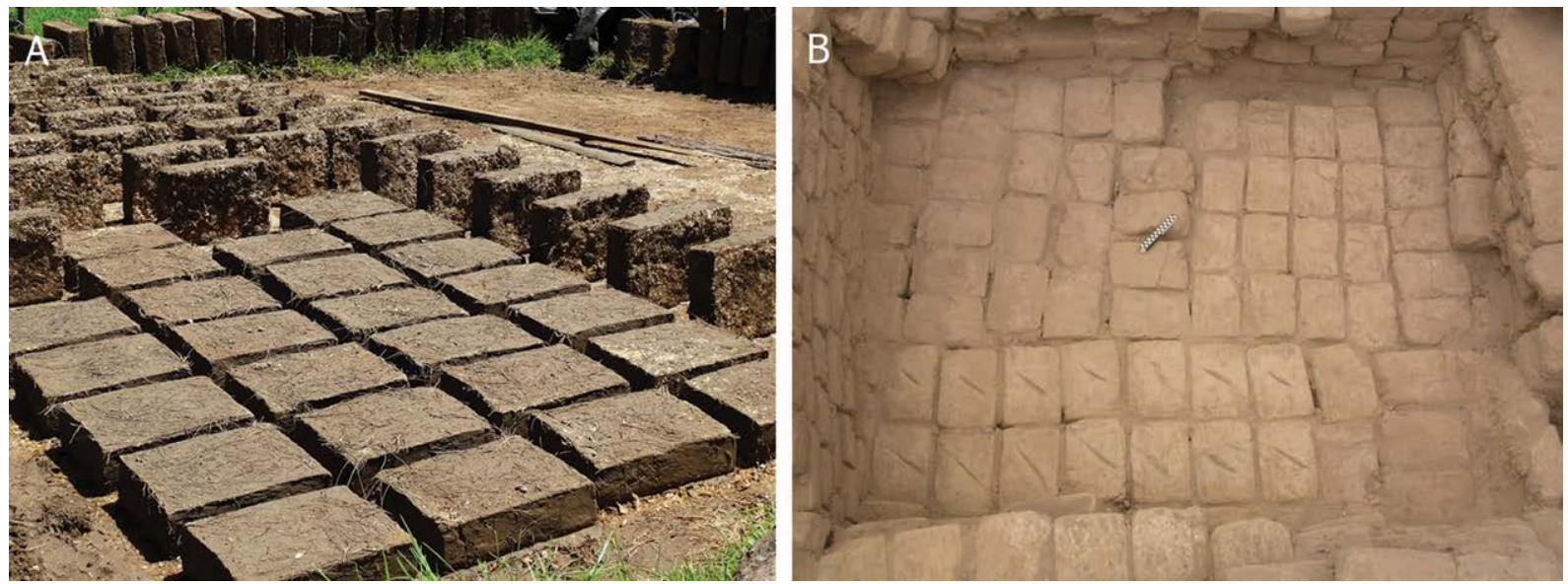

Figura 3. A) Producción de adobes hechos con molde en México (Jiménez y Guerrero, 2013, figura 6); B) Construcción con adobes hechos con molde y con la misma marca en una de sus caras, en Huaca de la Luna (Lambayeque, Perú), 400-70o d.C. (Tsai, 2014, figura 6).

(Aurenche, 1981; Wright, 1985, entre otros) o en el actual Perú en época prehispánica, en cronologías incluso del III milenio BC (Chirinos Cuadros y Zárate Aguinaga, 2011; Guillaud, 2011). También han sido hallados en los yacimientos franceses de adscripción neolítica de Jacques Coeur II (Montpellier), Jas de Biau (Millau) y La Capoulière (Mauguio) (Chausserie-Laprée y Roux, 2011; Jallot, 2003). En el caso de la península ibérica, esta técnica podría haberse empleado en el yacimiento calcolítico de El Cerro de la Virgen (Orce, Granada) (Kalb, 1969; Molina González, Cámara Serrano, Afonso Marrero y Spanedda, 2016; Schüle y Pellicer Catalán, 1966), como ha sido planteado (Belarte Franco, 2011). En cronologías contemporáneas, es conocido su empleo en diversos lugares del planeta, como en África, en Mali o Nigeria, donde son denominados tubali (Guillaud, 2011; Lauber, 2011; Oliver, 1971) y Asia, como en Omán o en la India (Guillaud, 2011).

Por su parte, el adobe fabricado con molde se documenta ya desde el VII milenio cal BC en Mesopotamia, Anatolia y en la actual Siria (Aurenche, 1981; Wright, 2009), en el antiguo Egipto a finales del periodo predinástico (Kemp, 2000), en Mesoamérica y la región andina en época prehispánica (Chirinos Cuadros y Zárate Aguinaga, 2011; Tsai, 2014, entre otros) y en la península ibérica, con seguridad, a partir del Bronce final y la primera Edad del Hierro (Belarte Franco, 2011; De Chazelles, 1995, 2011). 
En la actualidad, el adobe hecho con molde es una técnica de construcción con tierra ampliamente documentada y utilizada en el continente americano (Guerrero Baca, 2007; Rotondaro, 2004; Tomasi y Rivet, 2011, entre otros) y el asiático (Facey, 1997; Jerôme, Chiari y Borelli, 1999, entre otros), al norte de África y otras regiones del Mediterráneo (Correas Amador, 2013; Vissilia y Villi, 2010, entre otros), así como en Europa central (Güntzel, 1986; Knoll y Klamm, 2015, entre otros).

\section{Terrones}

Por último, la tercera técnica principal que emplea piezas de tierra es el terrón, en la que se utilizan como material constructivo bloques compactos, de diversa morfología y tamaño, extraídos directamente del suelo (Bardou y Arzoumanian, 1986; Guillaud, 2003), denominados generalmente terrones. Con estos bloques se edifican alzados, pero también pavimentos y cubiertas (Guillaud, 2003; Loveday, 2006; Milek, 2012). Dependiendo del tipo de suelo utilizado y de las diferentes tradiciones de puesta en obra, los terrones se disponen directamente unos sobre otros (Figura 5C), sin secado previo (Aurenche et al., 2011) o unidos mediante mortero tras dejarse secar al sol, como ha sido planteado para determinados casos del área andina en época prehispánica (Chirinos Cuadros y Zárate Aguinaga, 2011). Cabe diferenciar entre: a) el uso de bloques cortados y extraídos directamente de la superficie del terreno, que incorporan materia orgánica e incluso vegetación (Figura 5D), b) el empleo de bloques extraídos a mayor profundidad (Figura 4A) y c) la extracción de bloques de turba, empleados también como material constructivo, entre otros usos (Knoll et al., en prensa).

Son muy escasos los ejemplos de documentación de esta técnica en contextos arqueológicos. En el Perú prehispánico, se han documentado terrones, por ejemplo, en Huaca Ventarrón (Lambayeque), asociados al periodo arcaico, previos al 2000 a.C. (Chirinos Cuadros y Zárate Aguinaga, 2011). La presencia de alzados edificados con esta técnica - específicamente turf - se ha planteado en yacimientos como el de la Edad del Hierro de Mingies Ditch (Oxfordshire, Inglaterra) (Allen y Robinson, 1993). En cronologías recientes, se conoce el empleo constructivo de los terrones en Sudamérica (Viñuales et al., 2003), así como en diversas variantes en Norteamérica, las islas británicas, Islandia, Australia, Nueva Zelanda, India y en países africanos como Burkina Faso (Guillaud, 2003).

\section{Particularidades de la puesta en obra de las distintas técnicas}

La importancia de la diferenciación entre estas diferentes maneras de construir recae, sobre todo, en las diferentes implicaciones de tipo económico y social que el empleo de éstas puede conllevar. Así, en el amasado de bolas de barro, la mezcla se instala de manera directa tras su fabricación, por lo que su puesta en obra es un proceso rápido. Las piezas que puedan hallarse en contexto arqueológico como resultado de esta manera de colocar el barro presentarán un límite a su tamaño, marcado por la cantidad de mezcla que pueda manejarse con las manos y aplicarse a continuación en el muro en estado todavía húmedo, plástico. Por el contrario, en el caso de las piezas secadas previamente, nos encontramos ante módulos prefabricados, preconcebidos y puestos en obra de un modo similar al de, por ejemplo, mampuestos o ladrillos, necesitando generalmente ser unidos por mortero. Esto implica una manera distinta de construir y de concebir la edificación de las estructuras, con un resultado generalmente más regular, que requiere un proceso constructivo de mayor duración, una mayor inversión de energía y una serie de elementos añadidos respecto al caso anterior. Entre ellos, es necesario considerar los espacios físicos donde los adobes hechos a mano serían fabricados, en los que se produciría el proceso de secado y, en su caso, también el almacenamiento. Además, estas piezas pueden también ser transportadas y esta manera de construir requeriría el transporte de los bloques como mínimo desde su lugar de secado hasta la propia edificación en curso. Con todo ello, se requeriría probablemente 

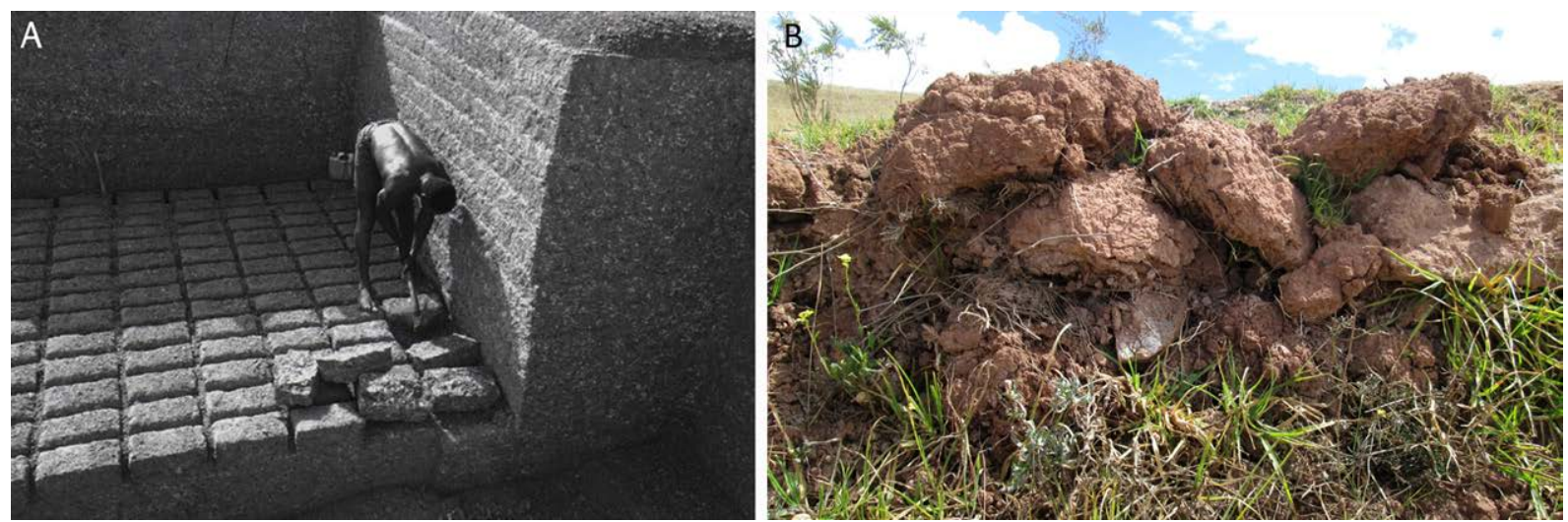

Figura 4. A) Extracción de terrones de laterita en Burkina Faso (Guillaud, 2003, figura 9); B) construcción con terrones ("champas") en Moray, Perú. Fuente: María Pastor Quiles.

A

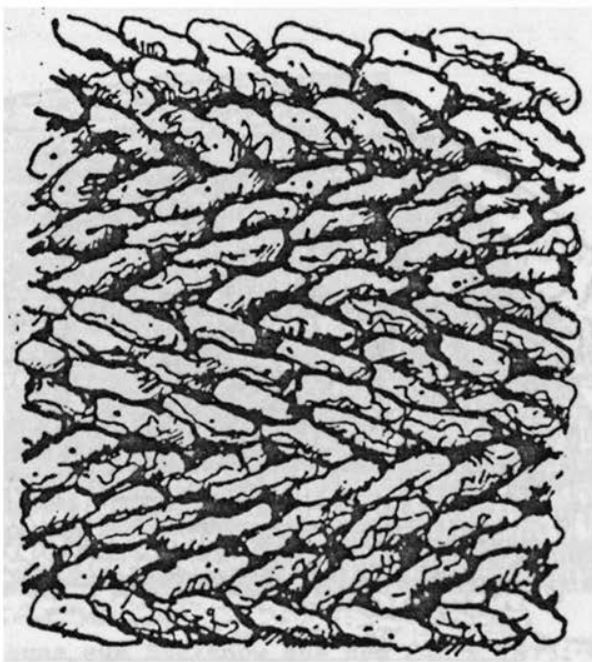

C

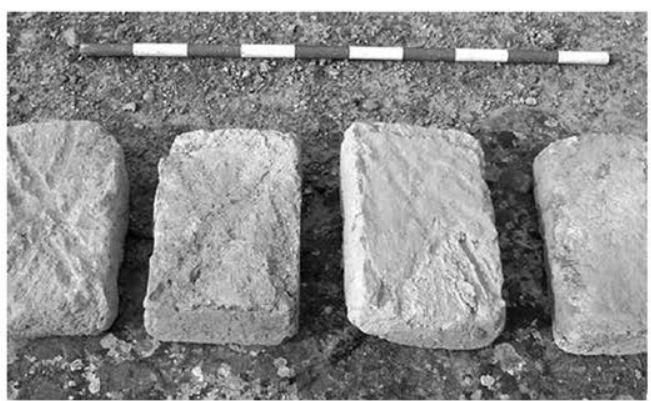

B
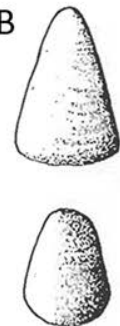

0.000
00000

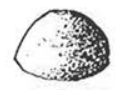

10000

IC
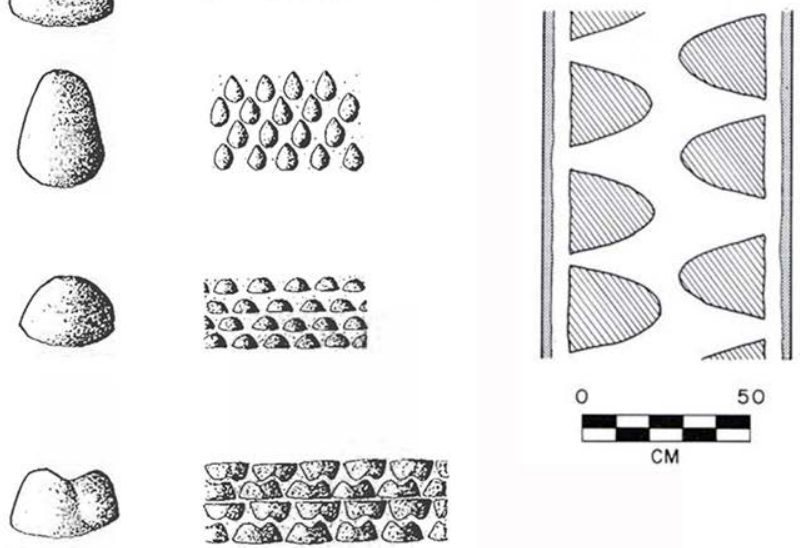

50

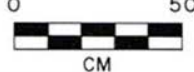

$\mathrm{CM}$

D
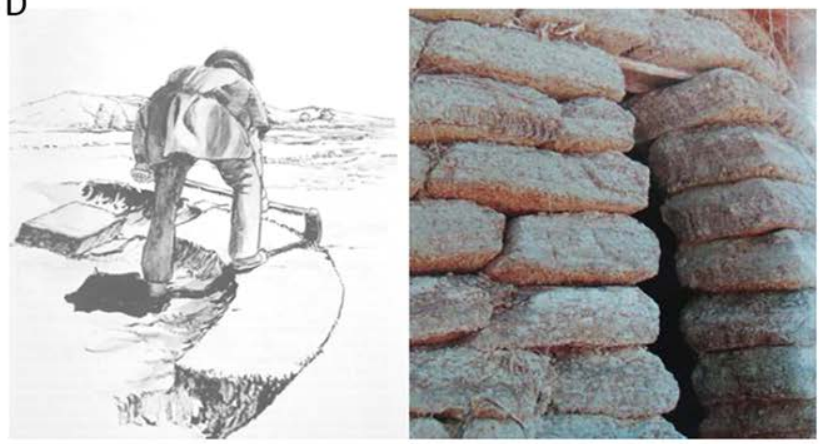

Figura 5. Cuadro-resumen de las diferentes técnicas constructivas que emplean módulos de tierra. A) Dibujo de la disposición de los módulos en la técnica del amasado de barro en forma de bolas o bloques, conocidos como "valky". Nezamyslice, República Checa (Güntzel, 1986, p. 369); B) izquierda: Formas que pueden adoptar los adobes hechos a mano (a partir de Doat et al, 1979, p. 108), derecha: ejemplo de su disposición, vista en sección horizontal, en una construcción de Huaca Lucía (Lambayeque, Perú), unidos con mortero (a partir de Chirinos y Zárate, 2011, p. 65); C) adobes rectangulares elaborados con molde procedentes del yacimiento protohistórico de San Cristóbal (Mazaleón, Teruel, España) (Fatás y Catalán, 2005, figura 6); D) extracción de terrones de la superficie del suelo y disposición de los mismos en un alzado (Castilla, 2004, p. 2).

un mayor número de personas implicadas en estos procesos constructivos y una mayor dedicación temporal a su producción estandarizada, lo que podría suponer un mayor grado de especialización laboral. Como resultado, se generaría un producto diferente, 
que requiere conocimientos y habilidades también distintas. Lo mismo ocurre con el terrón, obtenido del sustrato natural mediante el uso de herramientas, que ha de ser transportado y puede ser almacenado. Dependiendo de las condiciones del suelo del que sean extraídos los bloques, este proceso productivo requerirá una fase de secado, en unos espacios determinados. En todos los casos, la obtención y producción de estos módulos para construir conllevará alteraciones de diferente calado en el entorno, desde fosas de extracción y mezcla, montículos, hasta auténticas canteras.

\section{Criterios para la diferenciación de estas técnicas constructivas en contextos arqueológicos}

A pesar de las importantes diferencias entre las técnicas constructivas descritas y los procesos laborales implicados en su ejecución, las características de los módulos térreos resultantes y empleados en ellas pueden presentar considerables similitudes. Esto repercute negativamente en su diferenciación, incrementándose su dificultad cuando las piezas se encuentran aisladas o desplazadas del lugar que ocuparon originalmente en la construcción, y mucho más, si consideramos las alteraciones que se producen fruto de la acción de numerosos procesos postdeposicionales. Estos procesos no son infrecuentes en el estudio de estas técnicas constructivas desde una perspectiva arqueológica. Como piezas aisladas, con independencia del contexto en el que aparezcan -en superficie, en posición secundaria, derivada, incluso ya trasladadas y depositadas en los fondos museísticos-, éstas siguen siendo indicadores fundamentales del empleo de las técnicas descritas. El análisis de una serie de rasgos observables en estos diferentes tipos de módulos de tierra registrados en contextos arqueológicos puede contribuir a su mejor reconocimiento. Así, aspectos básicos a valorar son, por un lado, su morfología y tamaño y, por otro, su composición, con el uso de aditivos o estabilizantes.

\section{Morfología y tamaño}

La morfología y el tamaño de los módulos de tierra utilizados como material de construcción son los primeros elementos de juicio a considerar. En el caso del amasado en forma de bolas o bloques, la morfología de las piezas puede variar, desde formas más o menos esféricas a formas ovaladas u oblongas, estando condicionada por el estado húmedo o semi-húmedo de la masa. Del mismo modo, respecto al tamaño, las bolas o bloques de amasado de barro presentan también una longitud limitada, determinada por el volumen que puede ser amasado a mano y, sobre todo, por no encontrarse seca la pieza en el momento de su elaboración y consiguiente puesta en obra. Una cuestión fundamental respecto a la morfología de los módulos en la técnica del amasado se deriva también del estado de la mezcla de barro durante la puesta en obra: al no estar secos los bloques, las formas de los mismos se adaptan unas a otras, generando rehundimientos en sus superficies, un rasgo morfológico que queda preservado al secarse. Estos rehundimientos pueden ser visibles en las piezas cuando se observan de forma individual al encontrarse descontextualizados, suponiendo un claro indicador de la técnica del amasado en forma de bolas o bloques.

En la técnica del adobe, los bloques varían su morfología en función del procedimiento de su fabricación. Los adobes producidos manualmente pueden presentar formas muy diversas y sujetas a variabilidad entre ellas, al ser modelados a mano (ver Knoll et al., en prensa). Las más conocidas son las morfologías cónicas (Figura 2B) y semiesféricas (Chirinos Cuadros y Zárate Aguinaga, 2011; Doat et al., 1979), plano-convexas (Aurenche, 1981) y de contornos cuadrangulares, rectangulares y ovales. Algunos adobes hechos a mano son alargados, con formas denominadas "de barco", "de hogaza" o de "cigarro", como los documentados en los yacimientos neolíticos de Ganj Dareh, Sheikh el-Abad o Jani (Kermanshah, Irán) en los montes Zagros (Matthews, 2012, p. 201). 
En la elaboración con molde los adobes adoptan formas estandarizadas, siendo generalmente plano-convexas, cuadrangulares y rectangulares (Figura 3B). Nótese que, a nivel morfológico, los adobes hechos con molde pueden presentar, al igual que los hechos a mano, formas convexas en su parte superior, resultado de la regularización manual de las piezas en el molde, presentando así importantes similitudes en cuanto a la forma con unidades constructivas realizadas mediante otras técnicas. Las dimensiones de los adobes, tanto los hechos a mano como los fabricados con molde, podrían encontrar menos limitaciones que las relativas a los módulos de las otras técnicas. En este sentido, se ha apuntado que su tamaño puede alcanzar más de $1 \mathrm{~m}$ de longitud, siendo los casos más representativos los documentados en los asentamientos neolíticos de Ganj Dareh (Kermanshah, Irán) o Çatalhöyük (Konya, Turquía) (Aurenche, 1981; Stevanović, 2013), aunque el modo de fabricación o de colocación de estas piezas son cuestiones que todavía plantean dudas.

De este modo, un rasgo definitorio del empleo de la técnica del adobe fabricado con molde es la estandarización, en forma y tamaño, de las piezas resultantes. Los adobes, tanto los hechos a mano, como con molde, no presentarán los rehundimientos característicos del amasado en forma de bolas o bloques, al dejarse secar previamente a su inclusión en la construcción. En cambio, pueden presentar otro tipo de marcas, así como improntas del propio molde. $\mathrm{Y}$, al disponerse unidos con mortero, también podrían conservar restos de este.

Por su parte, en el caso de los terrones, su tamaño y morfología están condicionados por un lado por la forma de extracción de los mismos y los instrumentos empleados para ello y por otro por las características del suelo escogido como materia prima. Los ejemplos documentados muestran mayoritariamente morfologías cuadrangulares o rectangulares (Castilla Pascual, 2004). No obstante, en otros casos, como los hallados en Huaca Ventarrón (Lambayeque, Perú) (Chirinos Cuadros y Zárate Aguinaga, 2011), los terrones parecen mostrar formas irregulares y diferentes tamaños. En cualquier caso, también pueden presentar una cierta estandarización en formas y tamaños generada durante el proceso de corte del suelo y extracción de los bloques.

\section{Composición}

El otro criterio de importancia a tener en cuenta en la diferenciación entre las evidencias de las técnicas descritas es el de la composición. Existe una marcada diferencia entre los terrones, unidades extraídas directamente del suelo, y el resto de elementos aquí abordados, cuya masa es elaborada y manipulada antrópicamente. De este modo, los bloques y bolas de barro amasado y los adobes, hechos a mano o con molde, suelen presentar materias añadidas intencionalmente a la mezcla, a modo de estabilizantes (Bardou y Arzoumanian, 1986; Guerrero Baca, 2007; Houben y Guillaud, 1993, entre otros), algo que no es aplicable a los terrones. No obstante, los bloques extraídos del suelo también pueden contener, sobre todo superficialmente, elementos derivados de actividades antrópicas y materiales de desecho. Los bloques de tierra natural utilizados como material de construcción pueden contener restos de vegetales no seleccionados, pero la disposición y características de los mismos serán diferentes a las de las evidencias del empleo antrópico de materia vegetal añadida como estabilizante.

Las sustancias estabilizantes más comunes empleadas en estas técnicas constructivas - el amasado y el adobe - son las fibras vegetales, como la paja, pero también se conoce el uso de otras materias, generalmente de procedencia local, utilizándose de forma habitual residuos de actividades agrícolas y ganaderas. Son múltiples las materias orgánicas utilizadas como aditivos. A modo de ejemplo, el empleo de estiércol como estabilizante se conoce tanto en construcciones de amasado de barro (Aurenche, 1981; Baloi, 2001; Morriss, 2000) como de adobe (Facey, 1997; Rotondaro, 2004; Tomasi y 
Rivet, 2011; Vissac, Fontaine y Anger, 2012). En adobes se han documentado también otras materias estabilizantes, como el pelo de animal (Costi de Castrillo, Ioannou y Philokyprou, 2016; Tomasi y Rivet, 2011) o el betún (Kita, Daneels y Romo De Vivar, 2013).

En algunos casos, el análisis macroscópico podría ser suficiente para identificar algunos de los componentes de los elementos constructivos de tierra. Ahora bien, para caracterizar el material de forma más completa y exhaustiva es necesario llevar a cabo análisis de tipo físico - granulometría, plasticidad, compactación y propiedades mecánicas - o químico - contenido en materia orgánica, composición química y mineralógica-. Mediante micromorfología de lámina delgada, por ejemplo, puede analizarse si la distribución de las partículas de la tierra es homogénea o heterogénea, indicador de que haya sido mezclada en mayor o menor medida (Cammas, 2003). También puede determinarse el empleo intencional de restos vegetales para la estabilización de la mezcla, mediante la orientación más o menos paralela de sus evidencias en el interior del mortero de tierra derivada de una mezcla antrópica. Además, es posible estimar el grado de humedad del barro en el momento de su empleo, mediante la observación de vacuolas, burbujas de aire atrapado durante la mezcla, que se formaron durante la aplicación del barro en estado húmedo. Esto ha sido planteado tanto para la técnica del amasado (Wattez, 2003) como para la del adobe (Cammas, 2003; Matthews, 1995). Bajo estos parámetros, estamos en condiciones de establecer una primera distinción entre la técnica del terrón y las restantes, puesto que en la primera no se da la mezcla ni la manipulación antrópica del barro como tampoco el añadido de estabilizantes. El análisis de la composición y de estructura interna de los elementos de tierra sería determinante en este sentido.

\section{A modo de propuesta: rasgos para identificar las distintas técnicas a partir de sus módulos}

Considerando los aspectos descritos, podemos afirmar que, usados de forma aislada, ni la morfología, ni el tamaño, ni la composición serían criterios de diferenciación plenamente válidos por sí mismos para todos los casos. Sólo una combinación y valoración conjunta de todos estos rasgos permite la identificación fiable de la técnica constructiva utilizada. La morfología paralelepipédica de un adobe fabricado con molde puede ser similar a la de un terrón cortado del suelo con esa forma, al igual que el tamaño. Las formas ovaladas u oblongas y las dimensiones de las bolas de barro amasado pueden asemejarse a las presentadas por adobes hechos a mano. $Y$ un adobe hecho a mano o a molde puede tener una composición difícilmente diferenciable de la presentada por módulos de barro amasado.

Sin embargo, sí podemos reconocer algunos rasgos que, derivados de la técnica empleada, pueden ser determinantes para identificarla. Así, cabe resaltar:

1. En el caso de la construcción con amasado de barro mediante bolas o bloques, un rasgo que define de forma decisiva a estas unidades constructivas es de tipo morfológico, observable a nivel macroscópico y se deriva de su particular puesta en obra. Se trata de los rehundimientos o improntas de otros bloques de diversa magnitud generados en la superficie de los módulos, al ser aplicados, previamente a su secado, unos sobre y junto a los otros. La observación de las evidencias de una mezcla antrópica, observables a nivel micromorfológico, contribuyen a determinar el empleo de la técnica del amasado.

2. Respecto a la edificación con adobes, tanto hechos a mano como a molde, si los analizamos como unidades individuales y no formando parte de una estructura, 
las características que mejor permiten su identificación parecen ser, sobre todo, de tipo morfológico y apreciables a nivel macrovisual, pero relacionadas con su proceso de fabricación - no con su puesta en obra, como en el caso anterior-. En el adobe hecho a mano, los distintos módulos presentan generalmente formas similares entre sí, aunque sin la normalización característica de los adobes hechos con molde, ya que las formas se modelan individualmente, una tras otra. Los adobes producidos a mano son, como los resultantes de un molde, piezas secadas individualmente y que tiempo después son colocadas y unidas con mortero (Figura 5B). En los adobes hechos a mano podrían observarse ciertas marcas en sus superficies que se hubieran generado si en la disposición de éstos para su secado se colocaran tocándose unas piezas con otras, con una naturaleza diferente a los rehundimientos presentes en las piezas de barro amasado. Por su parte, en la producción con molde, el empleo de éste no sólo se puede inferir a partir de la morfología adoptada por las piezas y su estandarización métrica, sino que también podría llegar a hacerse a partir de las propias improntas del mismo. Por otra parte, si enfocásemos la diferenciación de las técnicas que aborda este artículo tomando como referencia los diferentes módulos ya colocados in situ, formando estructuras, el hecho de que los adobes, a mano y con molde, se dispongan unidos con mortero, sería un criterio diferenciador fundamental. De hecho, en contexto arqueológico, la observación de las capas de mortero uniendo los adobes es un rasgo definitorio de la edificación con esta técnica.

3. En el caso de los terrones, a la hora de distinguirlos individualmente, sería de gran relevancia el criterio de su composición y, en relación con esto, también el de la morfología de su estructura interna. La ausencia tanto de componentes añadidos de forma intencional a una masa como de las evidencias de mezcla comentadas más arriba sería clave en la identificación del uso del suelo natural y no de un producto elaborado de forma antrópica. De esta manera, los análisis micromorfológicos contribuirían sin duda a una mejor distinción entre el terrón y el resto de técnicas que emplean elementos modulares de tierra. De haberse utilizado bloques de tierra que conservaran la capa superior y externa del suelo, con la vegetación, esto podría observarse mediante la presencia de una línea de coloración más oscura. También la coloración derivada de la presencia de materia orgánica sería un rasgo característico del empleo de bloques de turba.

\section{Un ejemplo de construcción con elementos modulares de tierra en la Edad del Bronce de la península ibérica: la identificación del amasado en forma de bolas de Caramoro I (Elche, España)}

El caso que presentamos brevemente a continuación ilustra las posibilidades y las dificultades de la distinción entre los diferentes elementos modulares que pueden emplearse en la edificación con tierra.

El yacimiento de la Edad del Bronce de Caramoro I (Elche, España) se ubica en los territorios más septentrionales de la conocida Cultura de El Argar (Aranda Jiménez, Montón-Subías y Sánchez Romero, 2015; Lull Santiago, 1983), sobre un espolón rocoso en la margen izquierda del río Vinalopó (Figura 6). Fue excavado por Rafael Ramos Fernández en 1981 y en 1989 y 1993 se llevaron a cabo nuevos trabajos de excavación dirigidos por Alfredo González Prats y Elisa Ruiz Segura. Durante estas actuaciones fueron abordadas las técnicas y materiales constructivos empleados en el asentamiento, haciéndose referencia a que la parte oriental del llamado bastión o espacio H se habría levantado con piedras de gran tamaño y "adobes planoconvexos elaborados con barro y esparto, en los que hoy se aprecian claramente las improntas de las hebras vegetales" (González Prats y Ruiz Segura, 1995, pp. 87-90). 


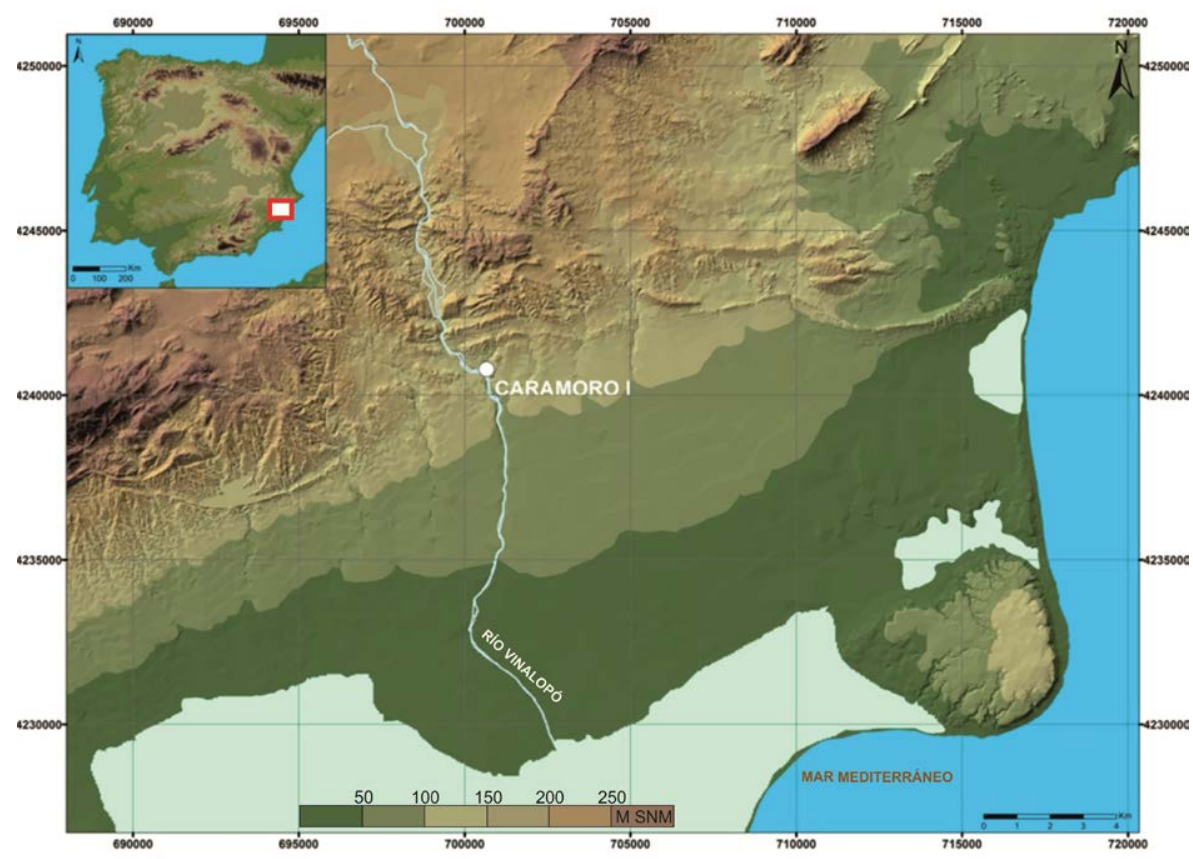

Figura 6. Ubicación del yacimiento de la Edad del Bronce argárico de Caramoro I (Elche, España).

1. Fueron llevadas a cabo bajo la dirección de Francisco Javier Jover Maestre, Sergio Martínez Monleón, Anna María Álvarez Fortes y Juan Antonio López Padilla y con la autorización de la Dirección General de Patrimonio de la Conselleria de Educación, Cultura y Deporte de la Generalitat Cultura y Deporte de la Generalitat
Valenciana. Expts. 2015/0305-A (SS. TT.: A-2015-109) y 2016/0315-A (SS. TT: A-2015-109).
En los años 2015 y 2016 se realizaron nuevas actuaciones arqueológicas ${ }^{1}$ que nos han permitido profundizar en los aspectos constructivos de este enclave argárico (Figura 7) e identificar dichos restos con una técnica muy poco conocida en este ámbito territorial y cronológico, el amasado de barro en forma de bolas. Así, hemos podido documentar un buen número de estas piezas de barro, tanto completas como fragmentos de ellas, de forma esferoide y oblonga en su mayoría, con improntas en sus superficies de material vegetal de considerable longitud. En estos materiales constructivos, con unas dimensiones variables (entre $10 \times 9 \times 6 \mathrm{~cm}$ y $17,5 \times 11,5 \times 6 \mathrm{~cm}$ ), se ha observado a nivel macroscópico en la composición de los morteros de barro la presencia de piedras, en algunos casos de considerable tamaño — hasta $6 \mathrm{~cm}$ de longitud-, así como de carbones, malacofauna y, ocasionalmente, hueso quemado y agregados de ceniza. Estas piezas modulares han sido identificadas, tanto entre los materiales constructivos de tierra procedentes de las excavaciones en Caramoro I de 1989 - conservados en el Museo Arqueológico y de Historia de Elche (MAHE)—, como todavía presentes en superficie en el propio asentamiento, junto con los ejemplares recuperados durante la excavación del año 2016.

Tras las nuevas intervenciones en el asentamiento, estamos en condiciones de plantear que el espacio $\mathrm{H}$ habría sido cerrado en su extremo meridional mediante un alzado de bloques de piedra de diverso tamaño y piezas de barro amasado de formas esferoides (Figura 8A). Esta plataforma presentaba una planta de tendencia rectangular-irregular y unas dimensiones máximas de $12,90 \mathrm{~m}$ en el eje SE-NO y 2,95 m en el eje NE-SO, delimitando un área aproximada de $33,65 \mathrm{~m}^{2}$. Esta construcción se habría reforzado también con tierra -UE 1807- Por otro lado, durante la campaña de excavación de 2016, en la zona de conexión entre el extremo oriental del espacio $\mathrm{H}$ y el arranque del antemural 2000, se excavó un nuevo tramo de alzado de barro - UE 1806- que habría sido construido también con una técnica basada en la aplicación manual de elementos de barro, mezclado con tallos largos de materia vegetal de forma oblonga, tamaño algo mayor al registrado en las piezas que cerraban el espacio $\mathrm{H}-23 \mathrm{x} 16 \mathrm{x}$ $9 \mathrm{~cm}$, en el caso de una de las piezas estudiadas de forma individualizada $-\mathrm{y}$ hechos también a mano (Figura 8B). 


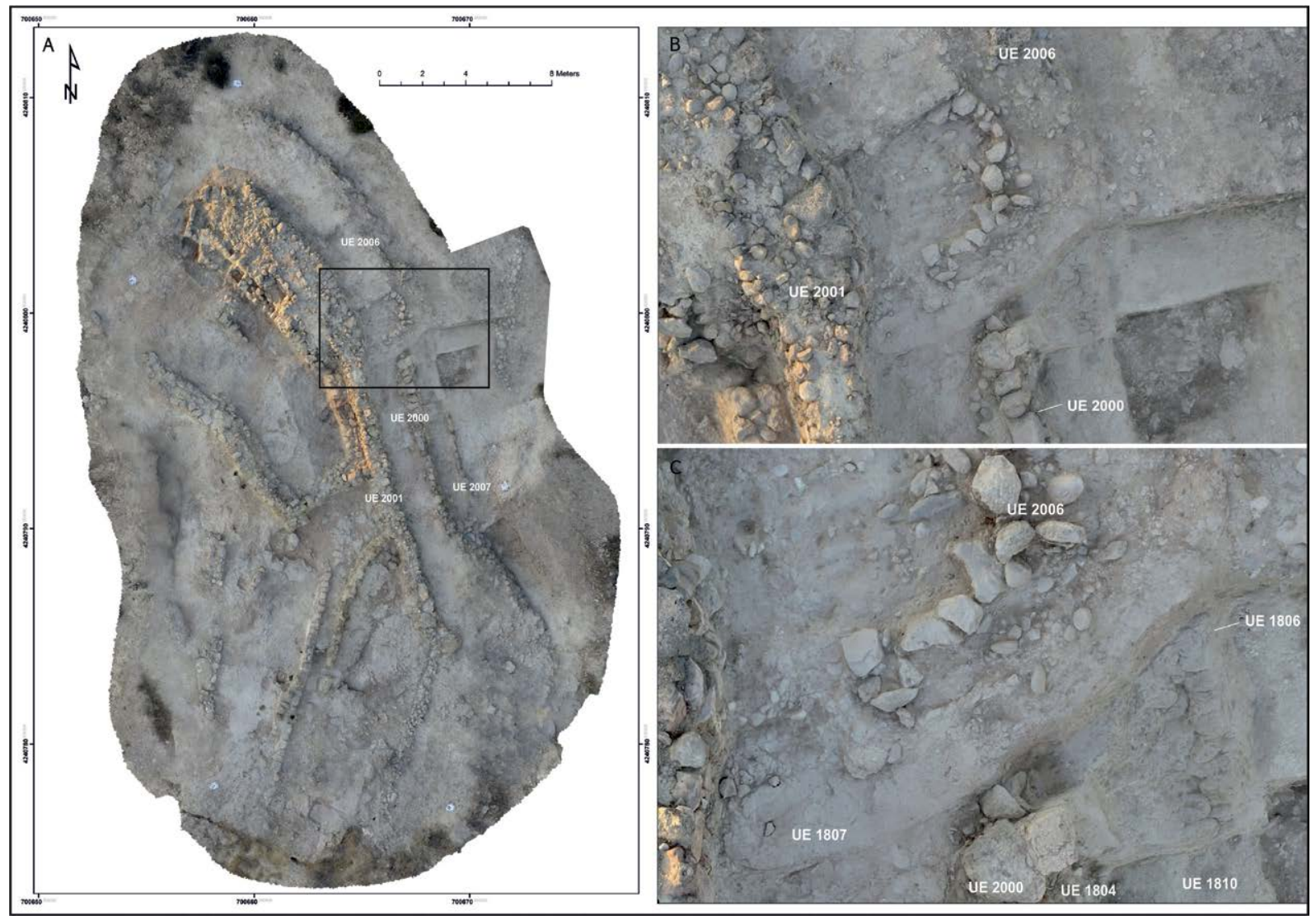

Figura 7. A) Ortofotografía de la planta del asentamiento de Caramoro I, donde se indica la zona oriental extramuros con los restos de construcciones de tierra y las principales unidades estructurales asociadas; $B$ ) visión ampliada de este espacio, donde se aprecia el cierre curvo del espacio $H$ en su unión con el muro UE 2001 y su relación con el antemural UE 2000; C) detalle de esta área, en el que se aprecia el refuerzo de tierra de la plataforma curva y el tramo de amasado de barro en forma de bolas (UE 1806).
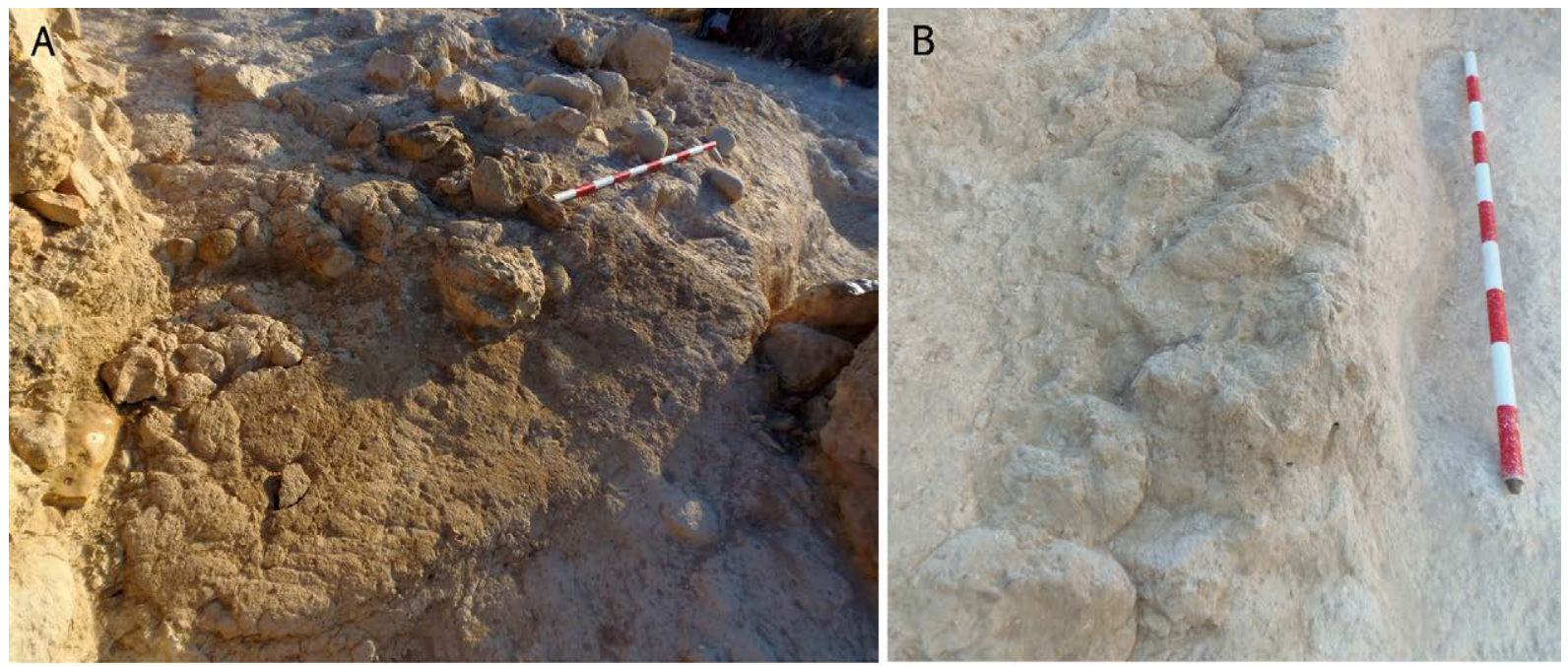

Figura 8. A) Vista del refuerzo curvo de tierra (UE 1807) en Caramoro I, desde su extremo meridional. Sobre él se habrían colocado las piezas semiesféricas; $B$ ) tramo de alzado de barro de Caramoro I construido mediante la disposición de elementos de forma oblonga en estado húmedo (UE 1806), visto desde su extremo meridional.

En la identificación de la técnica constructiva en la que se emplearon estas piezas ha sido determinante el hecho de que buena parte de ellas presentaran claros rehundimientos en sus superficies, generados al haberse colocado unas unidas a las otras antes del 
secado de la masa de barro (Figura 9). Por otra parte, fue fundamental el hallazgo del tramo murario UE 1806, que conservaba los diferentes módulos colocados in situ y que nos permitió observar, por primera vez en un asentamiento argárico, el resultado de la aplicación de la técnica del amasado de barro, en este caso, en forma de bloques.

Para el ámbito de El Argar han sido publicados diversos trabajos sobre el uso de la tierra en labores constructivas (Ayala Juan y Ortiz González, 1989; Ayala Juan, Rivera Núñez y Obón De Castro, 1989; Martínez Mira, Vilaplana Ortego, Such Basáñez, Juan Juan y García Del Cura, 2014; Pastor Quiles, 2014, 2017; Rivera Groennou, 2007, 2009, 2011), desconociéndose, por el momento, referencias al uso de esta técnica. No obstante, en Hoya Quemada (Mora de Rubielos, Teruel), un yacimiento arqueológico más septentrional adscrito al Bronce medio, sí parecen haberse documentado dos tramos de alzados construidos con amasado de barro en forma de unidades individualizadas, un "amasado de arcilla, agua y paja... colocando unas pellas de barro unas sobre otras" (Burillo y Picazo, 1986, p. 10). Así, consideramos que el empleo de esta técnica no estaría ausente en contextos arqueológicos de la Edad del Bronce en el ámbito de la península ibérica, como tampoco, posiblemente, en momentos anteriores, aunque su presencia no haya sido recogida explícitamente hasta ahora en la bibliografía. En esto ha podido repercutir la habitual falta de precisión en la denominación de las técnicas constructivas con tierra, apuntada por diferentes trabajos desde hace décadas (Belarte Franco, 2002; De Chazelles y Poupet, 1985; Pastor Quiles, 2017; Sánchez García, 1997).

\section{Conclusiones}

Terrones, bolas o bloques amasados y adobes, realizados con o sin molde, pudieron ser algunas de las técnicas constructivas empleadas en muchos más contextos geográficos y cronológicos que en los que han sido reconocidas hasta la fecha, como es el caso de los últimos milenios de la Prehistoria reciente en la península ibérica. Su adecuada identificación pasa por el desarrollo de un marco conceptual básico que contemple y compare las distintas técnicas, así como por la propuesta de criterios que permitan diferenciarlas, a lo que esperamos haber aportado algo de luz con este trabajo. Con todo lo expuesto, consideramos que existen una serie de cuestiones de relevancia a la hora de poder diferenciar entre el empleo de los distintos elementos modulares de tierra a los que nos hemos referido: bolas o bloques amasados de barro, adobes y terrones.

En primer lugar, el reconocimiento de estas técnicas depende, en gran medida, de un proceso de documentación y registro, consciente e informado, de los materiales de barro detectados en los procesos de excavación de contextos arqueológicos. Las características de la propia aparición de las piezas, de forma aislada o agrupada, y su disposición y relación entre ellas, en el caso de ser localizadas en contextos primarios, son rasgos que pueden permitir discriminar entre las posibles técnicas utilizadas. En cualquier caso, sin la identificación, documentación y/o recogida de los materiales, este tipo de evidencias ni siquiera podría ser objeto de estudio.

En segundo lugar, al completo registro en campo debe unirse la recogida, embalaje y traslado adecuado a los laboratorios de las piezas modulares que se consideren representativas para su posterior estudio. El estudio arqueológico pormenorizado de estas evidencias de construcción con tierra implica el desarrollo de un programa de análisis, tanto macroscópico, como microscópico, que permita caracterizar los módulos de barro en cuanto a morfología, tamaño y otras características formales, pero también a nivel compositivo.

En definitiva, consideramos que entre las técnicas constructivas con tierra que emplean elementos modulares, ya sea el amasado, el adobe o el terrón, una identificación fiable, 
A

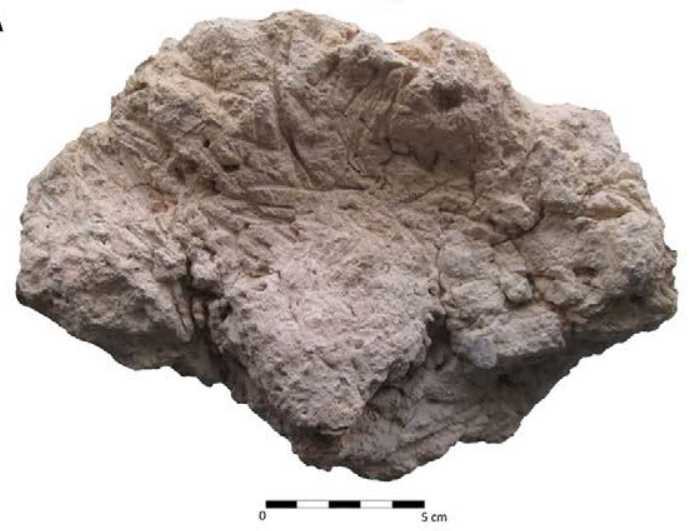

B

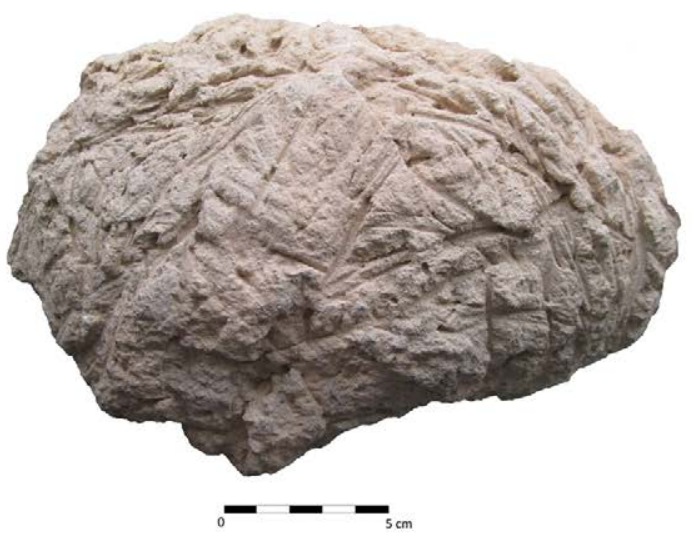

Figura 9. Fotografía de ambas caras de uno de los elementos de barro hallados en Caramoro I. A) Cara que presenta un rehundimiento central; B) cara contraria de superficie convexa. Fuente: elaboración propia.

especialmente a partir de unidades descontextualizadas, depende de una valoración de criterios distintos: la morfología y el tamaño de las piezas, así como la composición y, sobre todo, la información arqueológica obtenida durante el proceso de excavación.

En cualquier caso, la diferenciación de estas técnicas a partir de las evidencias arqueológicas no es una cuestión sencilla, ni a partir del estudio de piezas individualizadas ni tampoco mediante la observación de restos conservados en contextos arqueológicos primarios. A nivel morfológico, su distinción puede ser compleja en todos los casos, si además se encuentran afectados por procesos de alteración, erosivos o biológicos (ver, por ejemplo, Pastor Quiles, 2017), de forma considerable. Pero mucho más complejo será avanzar en el estudio del patrimonio arqueológico edificado si no somos conscientes del amplio y diverso uso constructivo de la tierra en el pasado y de las diversas formas de su puesta en obra, tratando de identificar las técnicas empleadas y de darles una denominación adecuada. La edificación mediante módulos de tierra tiene, sin duda, una presencia muy importante en los contextos arqueológicos, por lo que es necesario seguir profundizando en su estudio. La continuidad de las investigaciones en esta línea, todavía en sus inicios, proporcionará nuevos hallazgos, hipótesis y esperamos que también algunas respuestas.

\section{Agradecimientos}

Agradecemos a Alfredo González Prats y Elisa Ruiz Segura el proporcionarnos información sobre las excavaciones efectuadas en Caramoro I en 1989 y 1993, así como al Museo Arqueológico y de Historia de Elche (MAHE), en especial a Anna María Álvarez Fortes, el habernos facilitado el acceso a los materiales constructivos de dicho yacimiento para poder llevar a cabo su estudio. Damos las gracias también a las personas que han evaluado este manuscrito de forma anónima.

El presente trabajo ha sido realizado en el marco del proyecto de investigación "Espacios sociales y espacios de frontera durante el Calcolítico y la Edad del Bronce en el Levante de la península ibérica" (HAR2016-76586-P), financiado por el Ministerio de Economía y Competitividad del Gobierno de España. 


\section{Q Referencias citadas}

》 Agorsah, K. (1985). Archaeological implications of traditional house construction among the Nchmuru of Northern Ghana. Current Anthropology, 26(1), 103-115.

" Allen, T. y Robinson, M. (1993). The prehistoric landscape and Iron Age enclosed settlement at Mingies Ditch, Hardwick-with-Yelford, Oxon. Oxford: Oxford University Committee for Archaeology.

» Aranda Jiménez, G., Montón-Subías, S. y Sánchez Romero, M. (2015). The archaeology of Bronze Age Iberia. Argaric societies. Routledge Studies in Archaeology 17. Nueva York y Londres: Routledge.

» Arcelin, P. y Buchsenschutz, O. (1985). Les données de la Protohistoire. En Lasfargues, J., Architectures de terre et bois (pp. 15-27). Documents d'Archeologie Francaise 2. Paris: Ed. de la Maison des Sciences de l' Homme.

"Asensio Esteban, J. (1995). Arquitectura de tierra y madera en la Protohistoria del valle medio del Ebro y su relación con la del Mediterráneo. Caesaraugusta, 71, 23-56.

» Aurenche, O. (1981). La maison orientale. L'architecture du Proche Orient ancien des origines au milieu du IVème millénaire, Tome 1. Paris: Institut Francais d'Archeologie du Proche Orient.

" Aurenche, O., Klein, A., De Chazelles, C. y Guillaud, H. (2011). Essai de classification des modalités de mise en oeuvre de la terre crue en parois verticales et de leur nomenclature. En C. De Chazelles, A. Klein y N. Pousthomis (Eds.), Les cultures constructives de la brique crue. Actes du colloque international de Toulouse 16 et 17 mai 2008. Échanges transdisciplinaires sur les constructions en terre crue 3 (Montpellier 2011) (pp. 13-34). Montpellier: Éditions de l'Espérou.

" Avrami, E., Guillaud, H. y Hardy, M. (2008). Terra literature review. An overview of reasearch in earthen architecture conservation. Los Ángeles: The Getty Conservation Institute.

" Ayala Juan, M. y Ortiz González, R. (1989). Análisis por difracción de rayos X de enlucidos de las casas argáricas de los yacimientos el Rincón de Alméndricos y el Cerro de las Viñas de Coy, Lorca. Crónica del XIX Congreso Arqueológico Nacional (Castellón, 1987) 1, (pp. 323-328). Zaragoza: Universidad de Zaragoza.

" Ayala Juan, M., Rivera Núñez, D. y Obón De Castro, C. (1989). Improntas vegetales de adobes procedentes de la casa A del yacimiento argárico en llanura de Rincón de Almendricos, Lorca, Murcia. Crónica del XIX Congreso Arqueológico Nacional (Castellón, 1987) 1, (pp. 279-291). Zaragoza: Universidad de Zaragoza.

» Baloi, M. (2011). Archaeology and mud wall decay in the Bowirba area: an ethnoarchaeological study. Pula: Botswana Journal of African Studies, 15(1), 46-59.

» Bardel, P. y Rioult, J. (2006). Les premières formes de construction en bauge dans le bassin de Rennes. En E. Patte y F. Streiff (Eds.), L'Architecture en Bauge en Europe. Actes du Colloque Europée Organisé par le Parc Naturel Régional des Marais du Cotentin et du Bessin, Isigny-sur-Mer, 12-14 octobre 2006 (pp. 151-171). Les Veys: Parc naturel régional des Marais du Cotentin et du Bessin.

" Bardou, P. y Arzoumanian, V. (1986). Arquitecturas de adobe. Barcelona: Gustavo Gili.

» Bavay, G. (2006). Trente années d'investigations sur la bauge en Wallonie (Belgique). La bauge dans le contexte des architectures de terre. Historiographie et tendances. En E. Patte y F. Streiff (Eds.), L'Architecture en Bauge en Europe. Actes du Colloque Europée Organisé par le Parc Naturel Régional des Marais du Cotentin et du Bessin, Isigny-sur-Mer, 12-14 octobre 2006 (pp. 93-115). Les Veys: Parc naturel régional des Marais du Cotentin et du Bessin. 
» Belarte Franco, M. (2002). La construcció amb terra a la Protohistòria. Barcelona: Societat Catalana d'Arqueologia.

»Belarte Franco, M. (2011). L'utilisation de la brique crue dans la Péninsule lbérique durant la protohistoire et la période romaine. En C. De Chazelles, A. Klein y N. Pousthomis (Eds.), Les Cultures Constructives de la Brique Crue. Troisièmes Échanges Transdisciplinaires sur les Constructions en Terre Crue. Actes du Coloque International de Toulouse (16-18 Mai 2008) (pp. 13-32). Montpellier: Éditions de l’Espérou.

"Burillo Mozota, F. y Picazo Millán, J. V. (1986). El poblado del Bronce Medio de la Hoya Quemada (Mora de Rubielos, Teruel), Seminario de Arqueología y Etnología Turolense. Teruel: Colegio Universitario de Teruel.

»Cammas, C. (2003). L'architecture en terre crue à l'age du fer et à l'epoque romaine: apports de la discrimination micromorphologique des modes de mise en oeuvre. En C. De Chazelles y A. Klein (Dirs.), Échanges Transdisciplinaires sur les Constructions en Terre Crue. Actes de la Table-ronde de Montpellier, 17-18 novembre 2001 (pp. 33-53). Montpellier: Éditions de l’Espérou.

»Castilla Pascual, F. (2004). Estabilización de morteros de barro para la protección de muros de tierra. (Tesis Doctoral), Escuela Técnica Superior de Arquitectura, Universidad Politécnica de Madrid. España.

"Chausserie-Laprèe, J. y Roux, J. (2011). L'emploi de la brique crue à l'époque protohistorique (Vle-1er s. av. J.-C.) et ses antécédents dans le Midi de la France. En C. De Chazelles, A. Klein y N. Pousthomis (Eds.), Les Cultures Constructives de la Brique Crue. Actes du Colloque International de Toulouse 16 et 17 mai 2008. Échanges Transdisciplinaires sur les Constructions en Terre Crue 3 (Montpellier 2011) (pp. 213-243). Montpellier: Éditions de l'Espérou.

»Chirinos Cuadros, H. y Zárate Aguinaga, E. (2011). Historia de la construcción en Lambayeque. Periodos prehispánico y virreinal. (Tesis de Maestría en ingeniería), Universidad Nacional de Ingeniería. Lima, Perú.

»Correas Amador, M. (2013). Ethnoarchaeology as a tool for a holistic understanding of mudbrick domestic architecture in ancient Egypt. CUPAUAM, 39, 65-80.

"Costi de Castrillo, M., Ioannou, I. y Philokyprou, M. (2016). Comparative study of prehistoric, traditional and contemporary adobe bricks from Cyprus. Trabajo presentado en la International RILEM Conference on Materials, Systems and Structures in Civil Engineering, 22-24 August 2016 (pp. 61-70). Lyngby: Technical University of Denmark.

»De Chazelles, C. (1995). Les origines de la construction en adobe en Extreme-Occident. En A. Nickels y P. Arcelin (Eds.), Sur les pas des grecs en Occident... Hommages à André Nickels, Collection Études Massaliètes 4 (pp. 49-58). Paris: Errance.

» De Chazelles, C. (1999). À propos des murs en bauge de Lattes: problématique des murs en terre massive dans l'Antiquité. Lattara, 12, 229-254.

»De Chazelles Gazzal, C. A. (2011). La construction en brique crue moulée dans les pays de la Méditerranée, du Néolithique à l'époque romaine. Réflexions sur la question du moulage de la terre. En C. De Chazelles, A. Klein y N. Pousthomis (Eds.) Les cultures constructives de la brique crue. Troisièmes Échanges transdisciplinaires sur les constructions en terre crue, Actes du Coloque International de Toulouse (16-18 Mai 2008) (pp. 153-164), École d'architecture du Languedoc-Roussillon. Montpellier: Éditions de l'Espérou.

»De Chazelles, C. y Poupet, D. (1985). La fouille des structures de terre crue. Définitions et difficultés. Aquitania, 3, 149-16o.

"Dethier, J. (1982). Mud architecture: an old idea, a new future. Down to earth. Londres: Thames and Hudson. 
» Doat, P., Hays, A., Houben, H., Matuk, S. y Vitoux, F. (1979). Construire en terre. Paris: CRAterre-Éditions Alternatives.

» Facey, W. (1997). Back to earth: adobe building in Saudi Arabia. Londres: IB Tauris and Co.

» Fatás Fernández, L. y Catalán Garzarán, S. (2005). La construcción con tierra en la protohistoria del Bajo Aragón: el caso de San Cristóbal de Mazaleón. SALDVIE, 5, 131-141.

» Gauzin-Müller, D. (2017). Lehmarchitektur heute. Zürich: Hochschulverlag.

» González Prats, A. y Ruiz Segura, E. (1995). Urbanismo defensivo de la Edad del Bronce en el Bajo Vinalopó. La fortificación argárica de Caramoro I (Elche, Alicante). Estudios de Vida Urbana, 2, 85-105. Murcia: Real Academia Alfonso X El Sabio.

» Guerrero Baca, L. (2007). Arquitectura en tierra. Hacia la recuperación de una cultura constructiva. Apuntes, 2(2), 182-201.

» Guerrero Baca, L. (2018). Identificación y valoración del patrimonio precolombino construido con tierra modelada. Anales del Instituto de Arte Americano e Investigaciones Estéticas “Mario J. Buschiazzo”, 48(1), 125-141.

» Guerrero Baca, L., Soria, J. y García, B. (2010). La cal en el diseño y conservación de arquitectura de tierra. En Arquitectura construida en tierra, Tradición e Innovación. Congresos de Arquitectura de Tierra en Cuenca de Campos 2004/2009 (pp. 177-186). Valladolid: Cátedra Juan de Villanueva. Universidad de Valladolid.

» Guidoni, E. (1977). Arquitectura primitiva. Madrid: Aguilar.

» Guillaud, H. (2003). Construire en blocs découpés et mottes de gazon. En C. De Chazelles y A. Klein (Dirs.), Échanges Transdisciplinaires sur les Constructions en Terre Crue. Actes de la Table-ronde de Montpellier (17-18 novembre 2001), École d'architecture du LanguedocRoussillon (pp. 185-211). Montpellier: Éditions de l'Espérou.

» Guillaud, H. (2011). De traces en repères choisis: éloge terrestre de la brique crue. En C. De Chazelles, A. Klein y N. Pousthomis (Eds.), Les Cultures Constructives de la Brique Crue. Actes du Colloque International de Toulouse 16 et 17 mai 2008. Échanges Transdisciplinaires sur les Constructions en Terre Crue 3 (Montpellier 2011), (pp. 35-61). Montpellier: Éditions de l'Espérou.

» Guillaud, H., De Chazelles, C. y Klein, A. (Eds.) (2007). Les constructions en terre massive: pisé et bauge. Deuxièmes échanges transdisciplinaires sur les constructions en terre crue. Actes de la table ronde de Villefontaine (Isère), 28-29 mai 2005. Montpellier: Éditions de l'Esperou.

» Güntzel, J. (1986). Zur Geschichte des Lehmbaus in Deutschland. Kassel: Gesamthochschule Kassel, Universität des Landes Hessen.

» Gutherz, X., Jallot, L., Wattez, J., Borgnon, C., Roux, J., Thouvenot, Y. y Orgeval, M. (2011). L'habitat néolithique final de la Capoulière IV (Mauguio, Hérault): présentation des principaux résultats 2004-2007. En I. Senepart, T. Perrin y E. Thirault (Eds.) Actes 8e Rencontres Méridionales de Préhistoire Récente (Marseille 2008) (pp. 413-438). Marseille: Archives d'Écologie Préhistorique.

» Houben, H. y Guillaud, H. (1993). Earth construction: a comprehensive guide. Dunsmore: Intermediate Technology Development Group (ITDG) Publishing.

"Jallot, L. (2003). Exemples de constructions architecturées en terre crue dans les habitats du Néolithique meridional. En C. De Chazelles y A. Klein (Dirs.), Échanges Transdisciplinaires sur les Constructions en Terre Crue. Actes de la Table-ronde de Montpellier (17-18 novembre 2001), École d'architecture du Languedoc-Roussillon (pp. 169-184). Montpellier: Éditions de l’Espérou. 
» Jallot, L. y Wattez, J. (2015). Construire En Terre. Géoarchéologie-archéologie. Séminaire de recherche et de formation doctorale, Gème Séminaire sur l'habitat néolithique et 6ème Rencontre d'Archéologie preventive, Seconde table ronde sur les constructions en terre, Programme et Résumés (Montpellier, 23 et 25 Février 2015). Montpellier: Université Paul Valéry.

» Jerome, P., Chiari, G. y Borelli, C. (1999). The architecture of Mud: construction and repair technology in the Hadhramaut Region of Yemen. Association for Preservation Technology International (APT) Bulletin, 30(2/3), 39-48.

» Jiménez Zomá, N. J. y Guerrero Baca, L. F. (2013). La vivienda tradicional de adobe en los Altos de Chiapas, México: un patrimonio vivo". En Construcción con tierra. Patrimonio y vivienda. X CIATTI, Congreso de Arquitectura de Tierra en Cuenca de Campos, Cátedra Juan de Villanueva (pp. 37-46). Valladolid: Universidad de Valladolid.

» Jover Maestre, F., Pastor Quiles, M., Martínez Mira, I. y Vilaplana Ortego, E. (2016). El uso de la cal en la construcción durante la Prehistoria Reciente en el Levante de la península Ibérica: nuevas aportaciones para su identificación. Arqueología de la Arquitectura, 13, 1-18.

»Kalb, F. (1969). El poblado del Cerro de la Virgen de Orce (Granada). Actas del X Congreso Nacional de Arqueología (Mahón, 1967) (pp. 216-225). Zaragoza: Congresos Arqueológicos Nacionales.

» Kemp, B. (200o). Soil (including mud brick architecture). En P. Nicholson y I. Shaw (Eds.), Ancient Egyptian Materials and Technology (pp. 98-103). Cambridge: Cambridge University Press.

» Kita, Y., Daneels, A. y Romo De Vivar, A. (2013). Estudio químico para la identificación del aglutinante en muestras arquitectónicas prehispánicas. Trabajo presentado en XIII Seminario Iberoamericano de Arquitectura y Construcción con Tierra (Valparaíso, 20-30 agosto 2013). Santiago: Instituto Profesional DUOC.

»Klein, A. (2003). La construction en terre crue par couches continues, en Midi-Pyrénées. XVle-XXe siècles. Contribution à l'identification des techniques. En C. De Chazelles Gazzal y A. Klein (dirs.), Échanges transdisciplinaires sur les constructions en terre crue, Actes de la table-ronde de Montpellier, 17-18 novembre 2001 (pp. 417-437), École d'architecture du Languedoc-Roussillon. Montpellier: Éditions de l’Espérou.

»Knoll, F. y Klamm, M. (2015). Baustoff Lehm-seit Jahrtausenden bewährt. Archäologische, historische und rezente Zeugnisse des Lehmbaus. Ein Leitfaden für den Umgang mit "Rotoder Hüttenlehm" im archäologischen Befund, Kleine Hefte zur Archäologie in SachsenAnhalt 12. Halle: Landesamt für Denkmalpflege und Archäologie Sachsen-Anhalt.

»Knoll, F., Pastor Quiles. M., De Chazelles, C., Cooke, L. (en prensa). On cob balls, adobe and daubed straw plaits: A glossary on traditional earth building techniques (walls) in four languages. Halle: Landesamt für Denkmalpflege und Archäologie Sachsen-Anhalt.

» Lauber, W. (2011). Architektur der Dogon. Traditioneller Lehmbau in Mali. Ostfildern: Prestel.

" Loveday, R. (2006). Where Have All the Neolithic Houses Gone? Turf - an Invisible Component. Scottish Archaeological Journal, 28(2), 81-104.

» Lull Santiago, V. (1983). La Cultura del Argar. Un modelo para el estudio de las formaciones económico-sociales prehistóricas. Madrid: Akal.

» Martínez Mira, I., Vilaplana Ortego, E., Such Basáñez, I., Juan Juan, J. y García Del Cura, M. (2014). Cabezo Pardo. Análisis instrumental de materiales de construcción de barro del yacimiento argárico. En J. López Padilla (Coord.): Cabezo Pardo (San Isidro/Granja de Rocamora). Excavaciones arqueológicas en el yacimiento de la Edad del Bronce, Memorias Excavaciones Arqueológicas 6 Museo Arqueológico Provincial de Alicante (MARQ) (pp. 330-378). Alicante: Diputación de Alicante-Museo Arqueológico Provincial de Alicante. 
" Matthews, W. (1995). Micromorphological characterisation and interpretation of occupation deposits and microstratigraphic sequences at Abu Salabikh, Southern Iraq. En T. Barham y R. Macphail (Eds.), Archaeological sediments and soils, analysis, interpretation and management (pp. 41-74). Londres: Archetype.

» Matthews, W. (2012). Defining households: Micro-contextual analysis of Early Neolithic Households in the Zagros, Iran. En B. Parker y C. Foster (Eds.), New Perspectives on Household Archaeology (pp. 183-216). Winona Lake: Eisenbrauns.

» Milek, K. (2012). Floor formation processes and the interpretation of site activity areas: an ethnoarchaeological study of turf buildings at Thverá, northeast Iceland. Journal of Anthropological Archaeology, 31, 119-137.

» Mileto, C.y Vegas López-Manzanares, F. (2018). Earthen heritage in the USA: Approximation to constructive techniques. En C. Mileto, F. Vegas López-Manzanares, L. García-Soriano y V. Cristini (Eds.), Vernacular and Earthen Architecture: Conservation and Sustainability. SosTierra 2017, Valencia, 14-16 septiembre 2017 (pp. 179-184). Londres: CRC Press.

» Minke, G. (2001). Manual de construcción en tierra. La tierra como material de construcción y su aplicación en la arquitectura actual. Montevideo: Nordan-Comunidad.

» Molina González, F., Cámara Serrano, J., Afonso Marrero, J. y Spanedda, L. (2016). Innovación y tradición en la Prehistoria reciente del sudeste de la Península Ibérica y la Alta Andalucía (c. 5500-200o cal a.C.). En A. Sousa, A. Carvalho y C. Viegas (Eds.), Terra e água. Escolher sementes, invocar a Deusa. Estudos em homenagem a Victor S. Gonçalves (pp. 317-339). Lisboa: Centro de Arqueologia da Universidade de Lisboa.

" Morriss, R. (2000). The archaeology of buildings. Stroud: Tempus.

» Mylona, P., Wattez, J., Franel, Y. y Vigne, J. (2017). L'utilisation de la terre crue au PPNA à Klimonas (Ayios Tychonas, Chypre): construction et évolution du bâtiment communautaire (structure 10). Approche géoarchéologique. En J. Vigne, F. Briois y $\mathrm{M}$. Tengberg (Dirs.), Nouvelles Données sur les Débuts du Néolithique à Chypre, Séances De La Société Préhistorique Française 9 (pp. 105-118). Paris: Société Préhistorique Française.

» Nodarou, E., Frederick, C. y Hein, A. (2008). Another (mud) brick in the wall: scientific analysis of Bronze Age earthen construction materials from East Crete. Journal of Archaeological Science, 35, 2997-3015.

»Oliver, P. (1971). Shelter in Africa. Londres: Barrie and Jenkins.

» Ontiveros Ortega, E. (Coord.) (2006). Programa de Normalización de Estudios Previos Aplicado a Bienes Inmuebles. Sevilla: PH Cuadernos 19. Instituto Andaluz de Patrimonio Histórico, Junta de Andalucía, Consejería de Cultura.

"Pastor Quiles, M. (2014). Cabezo Pardo. Contribución a las formas constructivas de un hábitat argárico a partir del estudio de los elementos de barro. En López Padilla,J.(Coord.), Cabezo Pardo (San Isidro/Granja de Rocamora, Alicante). Excavaciones Arqueológicas en el Yacimiento de la Edad del Bronce. Memorias Excavaciones Arqueológicas 6 Museo Arqueológico Provincial de Alicante (MARQ), (pp. 306-321). Alicante: Diputación de Alicante-Museo Arqueológico Provincial de Alicante.

»Pastor Quiles, M. (2017). La construcción con tierra en arqueología. Teoría, método, técnicas y aplicación. Alicante: Servicio de Publicaciones de la Universidad de Alicante.

»Patte, E. y Streiff, F. (2006). L'architecture en bauge en Europe. Actes du colloque européen organisé par le Parc naturel régional des Marais du Cotentin et du Bessin, Isigny-sur-Mer, 12-14 octobre 2006. Les Veys: Parc naturel régional des Marais du Cotentin et du Bessin.

»Rivera Groennou, J. (2007). Aproximación a las formas constructivas en una comunidad de la Edad del Bronce: El poblado argárico de Peñalosa (Baños de la Encina, Jaén). Arqueología y Territorio, 4, 5-21. 
»Rivera Groennou, J. (2009): Micromorfología e interpretación arqueológica: aportes desde el estudio de los restos constructivos de un yacimiento argárico en el Alto Guadalquivir, Peñalosa (Baños de la Encina, Jaén). Cuadernos de prehistoria y arqueología de la Universidad de Granada, 19, 339-360.

» Rivera Groennou, J. (2011). Técnicas constructivas y relaciones sociales en una comunidad argárica del alto Guadalquivir, Peñalosa (Baños de la Encina, Jaén). En Memorial Luis Siret, I Congreso de Prehistoria de Andalucía, La tutela del patrimonio prehistórico (pp. 599602). Sevilla: Junta de Andalucía, Consejería de Cultura.

» Rotondaro, R. (2004). Arquitectura y construcción con tierra en la Argentina. Tradiciones, alternativas y direcciones futuras. Trabajo presentado en 1er Seminario Construcción con Tierra (pp. 1-28). Buenos Aires: Facultad de Arquitectura, Diseño y Urbanismo, Universidad de Buenos Aires.

» Sánchez García, A. (1997). La problemática de las construcciones con tierra en la prehistoria y Protohistoria peninsular. Estado de la cuestión. Actas del XXIII Congreso Nacional de Arqueología (Elche, 1995) 1 (pp. 349-358). Elche: Ayuntamiento de Elche.

»Schäfer, D. (2014). Lehm und seine Anwendung. Dünner-Lehmbrot-Bauweise. Clay Messenger 2, 1-4.

»Schüle, W.y Pellicer Catalán, M. (1966). El Cerro de la Virgen. Orce (Granada). Excavaciones Arqueológicas en España 46, Madrid: Servicio Nacional de Excavaciones Arqueológicas.

»Spencer, A. J. (1979). Brick Architecture in Ancient Egypt. Warminster: Aris and Phillips.

»Stevanovi, M. (2013). New Discoveries in House Construction at Çatalhöyük. En I. Hodder (Ed.), Substantive Technologies at Çatalhöyük: Reports from the 2000-2008 seasons, Çatal Research Project 9, British Institute of Archaeology at Ankara 48 (pp. 97-113). Los Angeles: Cotsen Institute of Archaeology Press-British Institute of Archaeology at Ankara.

»Syrova, Z. y Syrovy, J. (2006). La bauge en Moravie dans le contexte des constructions historiques en terre crue de la région danubienne. En Patte, E. y Streiff, F. (Eds.), L'Architecture en Bauge en Europe. Actes du Colloque Europée Organisé par le Parc Naturel Régional des Marais du Cotentin et du Bessin, Isigny-sur-Mer, 12-14 octobre 2006 (pp. 117131). Les Veys: Parc naturel régional des Marais du Cotentin et du Bessin.

» Tomasi, J. y Rivet, C. (2011). Puna y arquitectura. Las formas locales de la construcción. Buenos Aires: Centro de Documentación de Arte y Arquitectura Latinoamericana (CEDODAL).

» Tsai, H. (2014). Adobes y la organización del trabajo en la costa norte del Perú. Translating the Americas, 2, 101-144.

»Viñuales, G., Martins Neves, C., Flores, M. y Silvio Ríos, L. (2003). Arquitecturas de tierra en Iberoamérica. Salvador: Programa Iberoamericano de Ciencia y Tecnología para el Desarrollo (CYTED)-Subprograma XIV Tecnología para Viviendas de Interés Social (HABYTED)-Habiterra-Proterra.

»Vissac, A., Fontaine, L. y Anger, R. (2012): Recettes traditionnelles \& Classification des stabilisants d'origine animale ou végétale. Rapport du groupe de travail 1 , Projet Interactions argiles/biopolymères: Patrimoine architectural en Terre et stabilisants naturels d'origine animale et végétale (PaTerre+). Grenoble: CRAterre-École Nationale Supérieure d'Architecture de Grenoble (ENSAG).

»Vissilia, A. y Villi, M. (2010). Adobe and Timber Ties as Main Construction Materials for an Historic Greek Dwelling. International Journal of Architectural Heritage, 4(4), 295-319.

» Volkskundliche Kommission für Thüringen e.V (2009). Häuser aus Lehm und Stroh. Vergessene Bauweisen und Materialien. Hohenfelden: Hohenfeldener Hefte 4. 
"Wattez, J. (2003). Caractérisation micromorphologique des matériaux façonnés en terre crue, dans les habitats néolitiques du sud de la France: l'exemple des sites de JacquesCoeur (Montpellier, Hérault), du Jas-del-Biau (Millau, Aveyron) et de La Capulière (Mauguio, Hérault). En C. De Chazelles y A. Klein (Dirs.), Échanges Transdisciplinaires sur les Constructions en Terre Crue. Actes de la Table-ronde de Montpellier, 17-18 novembre 2001, (pp. 21-32). Montpellier: Éditions de L'Esperou.

» Wright, G. (1985). Ancient building in South Syria and Palestine. Leiden: E. J. Brill.

»Wright, G. (2009). Ancient building technology. Vol. 3: Construction. Leiden: E. J. Brill. 